\title{
OBTAINING PRESET PROPERTIES IN THE HYDROGENATION PROCESS BY CONTROLLING THE STATE OF PHASE BOUNDARY
}

\author{
Galina Metaksa ${ }^{1}$, Gulnaz Moldabaeva ${ }^{1 *}$ and Zhanat Alisheva ${ }^{1}$ \\ ${ }^{1}$ National technological Satbayev University of the Republic of Kazakhstan, Almaty, Republic of \\ Kazakhstan
}

\begin{abstract}
The introduction of science-intensive technologies that ensure a high level of energy content and restoration of ecological balance in places of extraction and processing of commercial resources is the main condition for the successful development of independent Kazakhstan. This paper concentrates on challenges of studying the mechanisms of chemical effects on oil-reservoir rocks functioning in order to increase oil recovery. Relevance of addressing the challenges is determined by necessity to increase profitability of fossil hydrocarbons mining. The article is prepared based on the results of the works carried out within the framework of the Program of the State Science Academies for 2013-2020 period. "Earth Sciences" geological library Section No.9, "Integrated discovery and conservation of the Earth subsoils" line of fundamental research \# 132, innovative processes of mineral deposits development and advenced processing of mineral raw materials", "The Fundamental Basis of Oil and Gas Industry Innovative Technologies" project, No.AAA - 0139-20180006. Key words: oil, hydrogenation, phase boundary, response, water, influence.
\end{abstract}

\section{Introduction}

The oil and gas field development system is formed at the initial stage of the deposit life cycle $[11,15,19,22,25,27,31]$. Selection of primary, secondary and tertiary methods (modes) for the dedicated operational facilities development is one of the key elements for the creation of the oil field development system $[9,17,20,23,24,26]$. The primary or natural regime for the oil and gas deposits development is named the aggregate of natural forces (energy types) that ensure the movement of oil or gas in the porous layer system to the faces of production wells $[10,12,14]$. Secondary methods of development or methods of reservoir pressuring maintaining (RPM) include methods of injecting working agents as the form of water (flooding) and natural gas $[13,16]$.

Tertiary methods of development applying in terrigenous and carbonate reservoirs are conditionally divided into two types, first one - the oil recovery enhancement method and

\footnotetext{
* Corresponding author: gulnazka 1978@mail.ru
} 
the second one - the advanced recovery method, depending on the prevailing influence on the multiplying factors of the equation for the oil recovery coefficient: coverage coefficient and displacement coefficient, respectively $[18,21,28-30]$. It is necessary to study the behavior of surface and near-surface layers placed in terrigenous and carbonate structures that are oil storage tanks, in order to understand the mechanisms of the oil recovery enhancement, because of any process can occures (melting, dissolution, chemical reaction) at phase boundary. Chemical decomposition of formation water molecules with the help of energy-storage substances (ESS) - is the new research line in the methods of impulse stimulation of formation. In this case, water is a hydrogen and oxygen supplier, which allows to obtain the hydrogenation and synthesis of new compounds. The change in the chemical composition of heavy hydrocarbons through oil hydrogenation under natural occurrence conditions is a pulsed effect that carried out by the help of water decomposition chemical reaction by using of activated aluminum [1-8]. Hydrogen precipitation provides to the hydrogenation reactions of all fractions of heavy oils. The scheme of applicability of the products of this fraction is shown below [1].

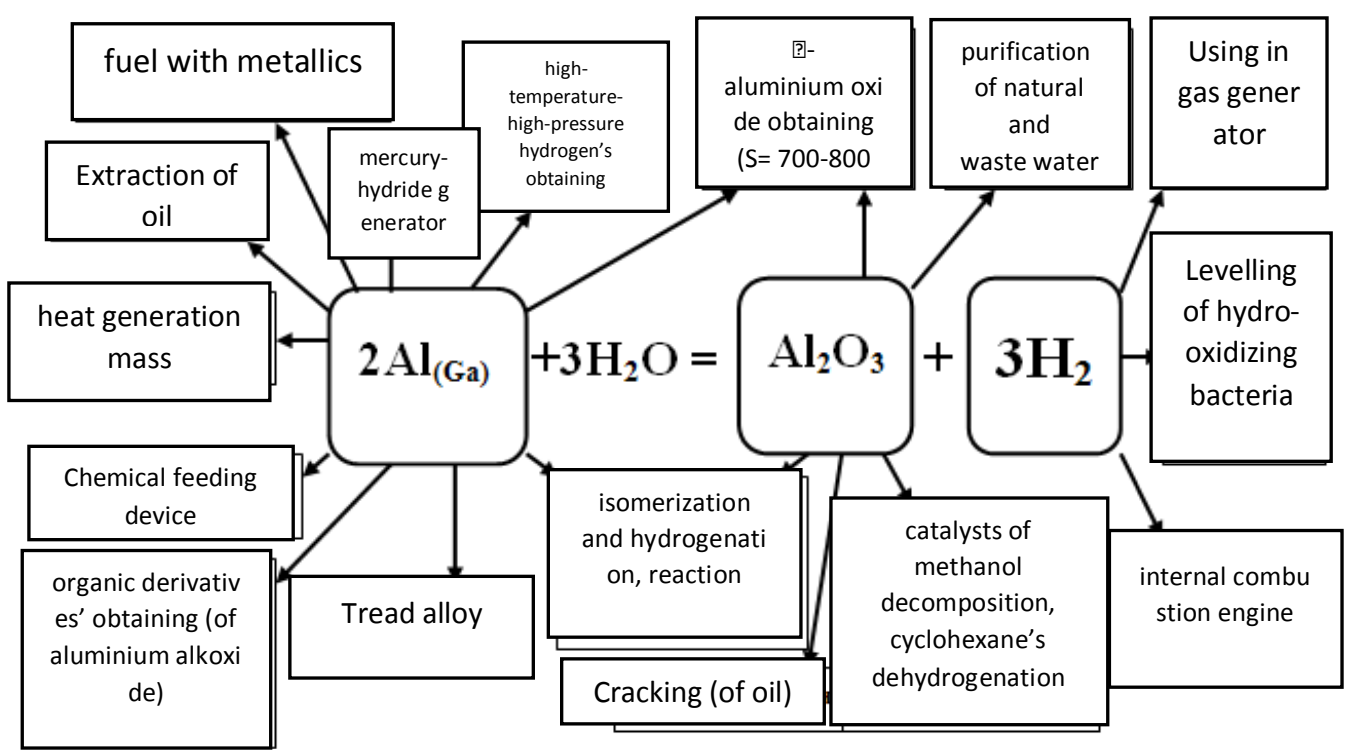

Fig. 1. Activated aluminum application and reaction products areas [1].

\section{Method of experimental research}

Research group of Kurapov G. G. were carried out industrial tests of the in the oil viscosity change by hydrogenation of its components at the "Embamunaigas" enterprise in 2016. During the first day of the test they received a positive result at enhancing the fluidity and at increasing productivity of the well. Well collation with the precipitated aluminum oxide, which requires a long time to be eliminated (2-4 weeks) is the negative side of the tests.

Thus, the results of these tests demonstrate the necessity to provide additional researches that, with the help of energy-storage substances (ESS), would prevent the negative consequences of the oil hydrogenation processes in natural conditions. 


\section{Results and discussions}

Since any processes start on the reacting components surface, the phase boundary state was studied by measuring the spectral composition of the responses at phase boundary. Here are the results of measurements of the spectral responses of water to an external influence, which was performed from a pulsed generator operating at the water decomposition frequency, i.e. $42.8 \mathrm{kHz}$ (The experimental procedure is described in [9]).

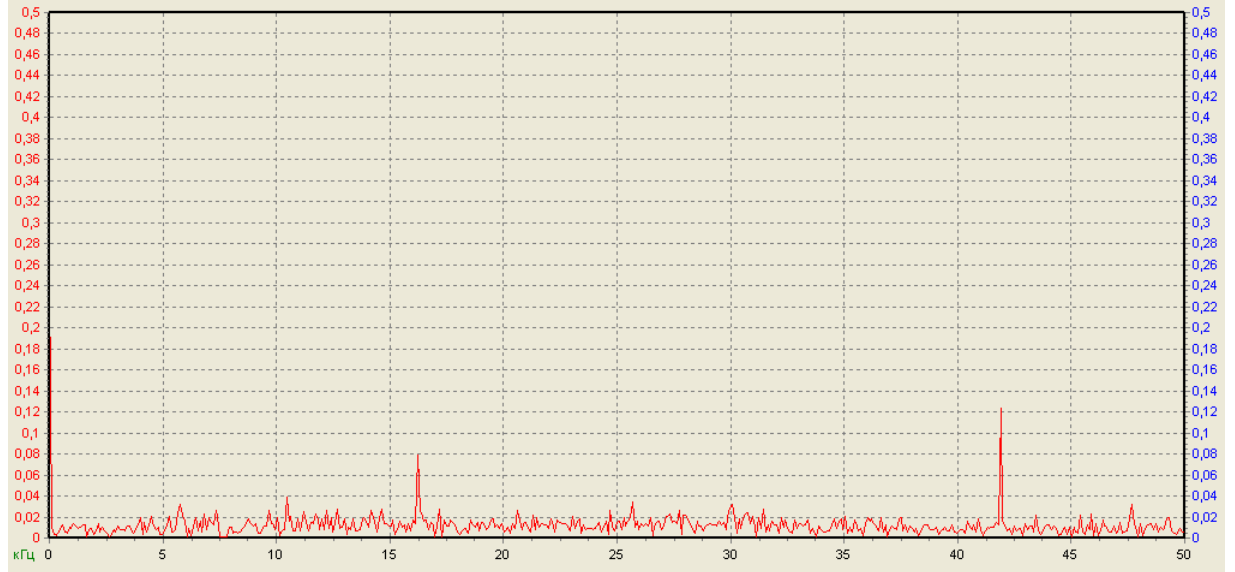

Fig. 2. Spectral composition of faucet mineralization water response at $42.8 \mathrm{kHz}$ frequency

Fig. 2 shows the spectrogram of the initial water of faucet mineralization, from which it can be seen that the response spectrum includes the fundamental frequency $(42.8 \mathrm{kHz})$, which has a maximum amplitude and the first two harmonics, the amplitude values of which are much smaller (2-3 times) than the main one.

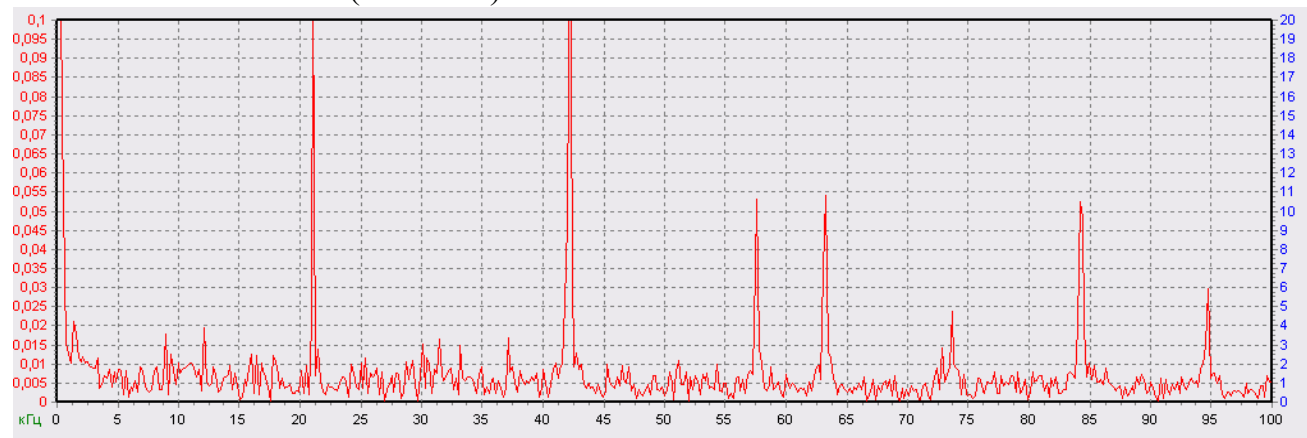

Fig. 3. Spectral composition of the of powdered sulfur response at a frequency of $42.8 \mathrm{kHz}$

Due to the fact that modern oils contain large amounts of sulfur and its compounds, powder and compressed sulfur pellets have been chosen for the model experiment, their responses are shown in Figures 3 and 4. It can be seen that, at this frequency, powdered sulfur produces responses that do not correspond to the harmonic series of the fundamental frequency of exposure, which is apparently due to the heterogeneity of the fractional composition of the powder (the powder is not sieved). The maximum response is fixed at the frequency of the exposure $(42.8 \mathrm{kHz})$, in addition, responses to 21, 57, 63, 84 and 95 $\mathrm{kHz}$ are seen. 


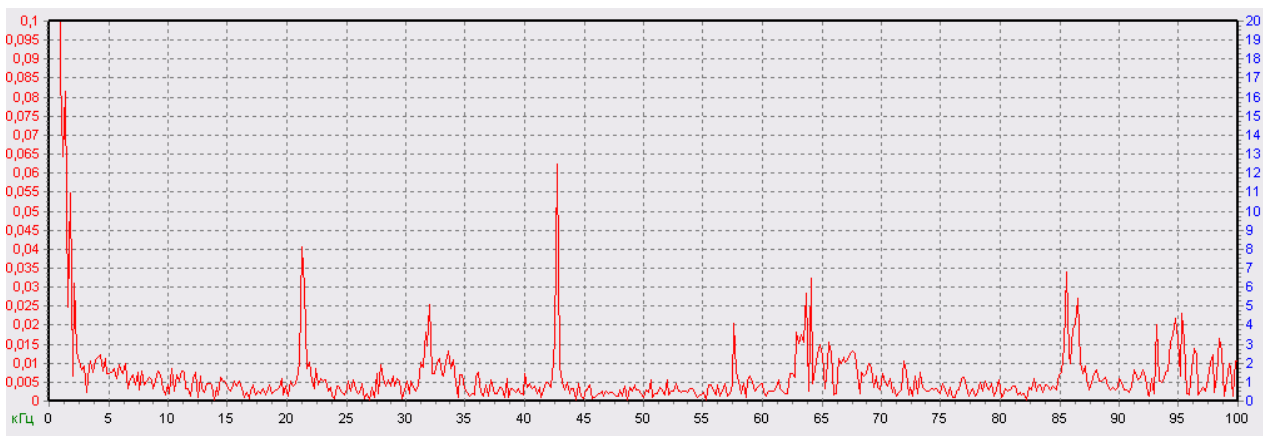

Fig. 4. Spectral composition of the response of pressed, coated with water, sulfur at a 42.8 $\mathrm{kHz}$ frequency

Covered with water film, pressed sulfur (Figure 4), gives the maximum response at the frequency of exposure, and the harmonic components of this response have a 2 or 3-watt structure under the same conditions of measurement. Speaking on language of physics this means that the resonant conditions correspond to the other dimensionality of the response structural elements. In other words, another structure of the phase boundary is fixed. For the triplet response, it is possible to represent the layered structure of the phase boundary between phases according to the scheme given below (Fig. 5).

1

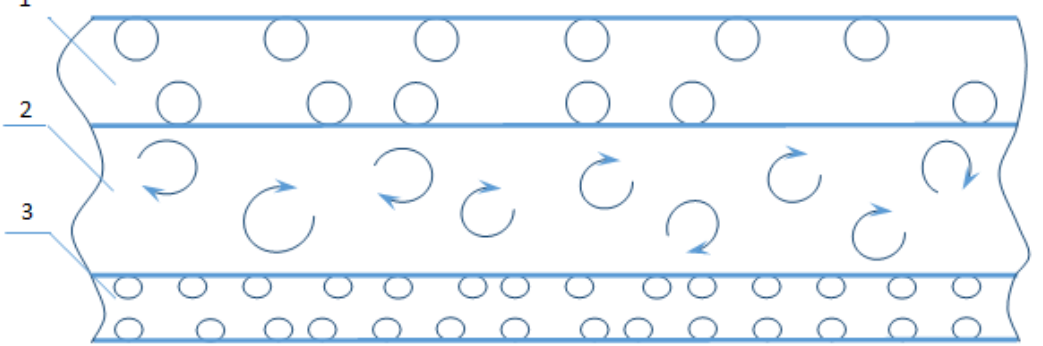

Fig. 5. Hypothetical phase boundary structure

(1-Low-frequency response, 2-Base signal, 3-High-frequency response)

With a shown above phase boundary structure, the conductivity of the base signal, that is, its efficiency, depends on the state of the upper and lower boundaries, and accordingly, in the case of hydrogenation, at least three reaction products can be present at the output, which is confirmed by the results of [9-12]. It is shown here, that this effect can be used to obtain prescribed properties in petroleum compositions via external exposure on the phase boundary by electromagnetic impulse exposure at the frequency of water decomposition. In this paper, additional possibilities for controlling the phase boundary structure were revealed through the use of powders possessing different dispersity. This is a new effect, based on the achievements of other branches of science such as optics (photoconverters), metallurgy [13-14], tribotechnics, etc.

The principal novelty of our development is the use of the water decomposition frequency that experimentally discovered by Puharich A. [15], the physical substantiation of which is still missing in our science. Following the classical logic of calculating the frequency by dividing the propagation velocity of the external exposure by the wavelength (the scale of the water structural components), we can see a complete discrepancy with experiment. The calculation performed according to Kepler's third law [16] gives a logical result:

$$
\mathrm{R}^{3} / \mathrm{T}^{3}=\mathrm{K}=3,36 \times 10^{-18}=5.12 \mathrm{~nm} \text { (nanometer). }
$$


$\mathrm{R}$ - interaction range;

$\mathrm{T}$ - interaction period.

The aggregate of experimental results show that the state of the phase boundary is the basis for controlling the chemical composition of hydrocarbons in the chemical impulse exposures.

\section{Conclusions}

1. To reveal the mechanism for controlling the phase boundary in "oil-water" compositions, an experimental setup has been created to measure the spectral composition of the boundary responses when the water decomposition frequency acts on it.

2. The results of physical modeling on the research of the "water-solid" phase boundary structure have shown that any inhomogeneity, that prevents the transmission of an exposure signal, causes response at the fundamental frequency and at harmonic frequencies, this response may cause a offshift of low or high frequencies.

3. The effect of the appearance of the layered structure of the "water-solid" phase boundary, which allows controlling the mechanism of interaction of the separated phases during the external exposure, is discovered.

\section{References}

1. R.G. Samurzina, Production of hydrogen and aluminum oxide in the reaction between aluminum and water. Doctoral dissertation, Almaty city. p. 165. (1984).

2. R.Zh. Abirov, A.G. Mukhamedova, B. Panabekkyzy, Zh.Zh. Abirov, A.A. Nesterkin. Oil and gas field business journal. 5.15-19. (2016)

3. R.G. Sarmurzina, D.V. Sokolovskii and others. Head of the report of VI Petrochemistry Conference, Atyrau city (former - Gurev), (1984.).

4. Iu.P. Zheltov, N.A. Eremin, E.S. Makarova. Oil Industry. 11. p. 28-32. (1993).

5. P.F. Bernath. Chem. Soc. Rev. 25. pp. 111-115. (1996).

6. P. F. Bernath. Annu. Rep. Prog. Chem., Sect. C: Phys. Chem. 96. pp. 177-224. (2000).

7. Encyclopedia of Spectroscopy and Spectrometry. Lindon J. 2nd Ed. Academic Press. p. 3312. (2010).

8. D.V. Sokolovskii, Hydrogenation in solutions. // Almaty city, "Nauka" Publishing house. p. 364. (1979).

9. USSR Certificate of authorship No.1282462, production process of $\square$-aluminium oxide // G.G. Kurapov and others.

10. Zh.N. Alisheva, G.P. Metaksa. "Sodruzhestvo" Russian - Chinese scientific journal. Monthly scientific journal of research and practice conference. 16 (2). pp. 4-9. (2017).

11. V.K. Bekbaeva, G.P. Metaksa. Bulletin of the National Engineering Academy of the Republic of Kazakhstan. 1 (67). pp.39-45. 2018.

12. G.P. Metaksa, Theoretical bases of rocks conditions estimation and the forecasting. Academic Publishing. ISSN: 978-3-659-79250-2. (2015).

13. N. Buktukov, G. Metaksa, E. Vikhrachev. Bulletin of national technological Satbayev University of the Republic of Kazakhstan. 1/1 9580. 198-203. (2007).

14. N.S. Buktukov, G.P. Metaksa, E.P. Vikhrachev, G.Zh. Moldabaeva. Collection of scientific papers of D.A. Kunaev Institute of Mining. 73. Almaty city. pp. 94-99. (2007).

15. USSR Certificate of authorship. Method of metals and alloys working. // G.P. Metaksa, Kurapov and others., priority as of September 12, (1977).

16. Andria Henry Pucharich // Patent USA. No.9.394.230 dated July 19, (1983).

17. B.M. Iavorskii, A.A. Detlaf. The Handbook of Physics. p. 942. (1974). 